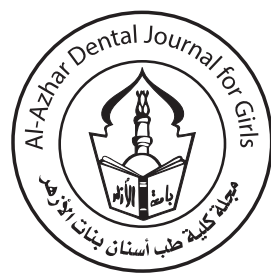

\title{
Evaluation of GRP 78 Expression in Salivary Gland Tumors
}

\author{
Amany M. Abdallah ${ }^{1 *}$, Eman A. Abo Hager ${ }^{2}$, Adel A. Shouman ${ }^{2}$
}

Codex : 35/1907

azhardentj@azhar.edu.eg

http://adjg.journals.ekb.eg

DOI: $10.21608 /$ adjg.2019.7496.1076

\section{KEYWORDS}

GRP78, immunohistochemistry, salivary gland tumors

\begin{abstract}
Purpose: The purpose of this work stayed to evaluate the expression of GRP78 as a prognostic indicator of aggressiveness in tumors of the salivary gland and to relate its expression with the salivary gland tumors biological behavior. Material and Method: 80 cases of salivary gland tissues were collected as paraffin embedded blocks: 30 benign cases (15 pleomorphic adenoma and 15 Warthin's tumors) and 45 malignant cases ( 15 carcinoma ex pleomorphic adenomas, 15 mucoepidermoid carcinomas in addition to 15 adenoid cystic carcinoma). Additionally, 5 normal salivary gland tissues. Using GRP78 antibody, an immunohistochemical investigation was done for all specimens. Results: The greatest mean area percent of GRP78 immunoexpressioin was in malignant variants of salivary gland tumors, followed by benign variants of salivary gland tumors and the least value recorded in normal salivary gland tissue. Conclusion: According to the current study, GRP78 is considered as a useful marker for diagnosis of malignancy of salivary gland.
\end{abstract}

\section{INTRODUCTION}

Salivary gland tumors are rare, dissimilar groups that account fewer than $5 \%$ of head and neck tumors and about $0.5 \%$ of all malignancies. They vary considerably in their phenotypic, biological, and clinical behavior, and they differ in their responsiveness to systemic therapies ${ }^{(1)}$. Tumors of the salivary glands show greatest histological diversity between human tumors. A broad morphologic variety presents between different types of tumor and sometimes within a separate tumor mass.

* Paper extracted from Doctor thesis entitled "Evaluation of Beclin 1, GRP78 and CD34 Proteins Expression in Some Salivary Gland Tumors".

1. Assistant Lecturer of Oral and Dental Pathology, Faculty of Dental Medicine for Girls, Al Azhar University. email: y.t.lawyer01003098055@gmail.com

2. Professor of Oral and Dental Pathology, Faculty of Dental Medicine for Girls, Al Azhar University. 
In addition, the occurrence of mixed tumors, dedifferentiation and the propensity of malignant transformation of some benign salivary gland tumors make this group of lesions one of the most exciting and challenging in the head and neck ${ }^{(2)}$.

The endoplasmic reticulum (ER), an organelle monitors protein folding where synthesis, maturation, and secretion of proteins occur. When a cell suffer from stressful conditions, like starvation, redox imbalance, abnormal protein glycosylation, or defect of protein folding, the normal functioning of the ER in protein synthesis is disturbed, and a stress state of the ER begin. As accumulation of misfolded proteins occure, the unfolded protein response (UPR) is started to counter these stress effects. The final outcome of ER stress determines whether a cell survives or experiences programmed cell death. The up regulation of glucose-regulated protein $\mathrm{kDa}$ 78 (GRP78) (a key ER chaperone) is one of the most important protective mechanisms induced by UPR ${ }^{(3,4)}$. GRP78 is a heavy chain immunoglobulin binding protein $(\mathrm{BiP})$, it is also recognized as a member of the heat shock protein 70 (Hsp70) family, whose function is to preserve cytosolic homeostasis. GRP78 binds to nascent polypeptides and also considered as a calcium binding protein. It is repressed by a high calcium ions concentration, and its ATPase activity is triggered by calcium exhaustion ${ }^{(5)}$.

As mentioned, GRP78 controls protein folding and enables protein translocation in the ER and it is also complicated in ER stress. Hypoxia, glucose deficiency, inflammation and $\mathrm{Ca} 2+$ depletion can promote GRP78 mRNA transcription and translation to preserve the stability of the ER and to dismiss severe ER stress ${ }^{(6)}$. Most of these discovered actions depend on its cell position. GRP78 is mainly present in the ER lumen due to the existence of an ER signaling peptide, although under some situations it is translocated to the cytoplasm, nucleus, mitochondria, or the cell membrane or even secreted. So, different GRP78 locations prime to activate different molecular signaling actions ${ }^{(7,8)}$. GRP78 plays a double role in tumor cells. GRP78 induce dormancy of tumor cells in early stages of tumor development. Alternatively, at more late stages of tumor progression, in which tumor showing more severe stress, GRP78 has been shown to accelerate tumor progression through the pro-survival and pro-metastatic functions of it ${ }^{(9,10)}$. Increased GRP78 levels are known in various solid tumor types, like prostate, melanoma, head and neck, lung, breast, brain, colon, and hepatocellular carcinoma. Also, high GRP78 levels correlated with gastric, breast, and liver cancer metastasis. On the other hand, a report found decreased expression of GRP78 in models of mouse prostate cancer. These unpredicted results might be due to time-dependent changes ${ }^{(9,11,12)}$.

It was reported that GRP78 expression was closely related with tumor size and stage, lymphatic as well as distant metastasis, and GRP78 positive expression was clarified as an important independent marker for expecting poor outcome in patients with oral squamous cell cancer. However, it has been pronounced that the patients with weak GRP78 expression have a higher prevalence of metastasis to lymph node than those with strongly GRP78 in oral squamous cell cancer ${ }^{(13,14)}$. GRP78 was clarified as an negative prognostic marker for ACC patients, having a significant correlation with proliferation and angiogenesis. The high GRP78 expression seemed to be associated with a solid pattern, demonstrating no significant difference. In another report, however, positive expression of GRP78 has been described to be significantly associated with a tubular or cribriform pattern and longer overall survival, indicating no relationship between its positive expression and tumor invasiveness such as vascular and lymphatic invasion ${ }^{(15,16)}$.

Therefore, the present study has been done aiming to evaluate GRP78 expression in benign, malignant salivary gland tumors in addition to normal salivary gland tissues. And to correlate between GRP78 expression with histopathologic findings via mean of the immunohistochemical technique. 


\section{MATERIALS AND METHODS}

\section{Case selection}

The specimens of this study were retrieved as a paraffin embedded blocks from the archives of Oral and Dental Pathology Department, Faculty of Dental Medicine for Girls, Al-Azhar University and Oral Pathology Department, Faculty of Dentistry, Alexandria University.

The cases divided into three sets: Group I, control group including five cases of normal salivary gland tissue. Group II, benign salivary gland tumors, including 30 cases divided into, 15 cases of pleomorphic adenoma (PA), 15 cases of Warthin's tumor. Group III, malignant salivary gland tumors, including 45 cases divided into, 15 cases of carcinoma ex pleomorphic adenomas (Ca ex PA),15 cases of mucoepidermoid carcinoma (MEC) with different grades, and 15 cases of adenoid cystic carcinoma (ACC) representing the different patterns according to $\mathrm{WHO}^{(17)}$.

\section{Immunohistochemical analysis}

$5 \mu \mathrm{m}$ thickness of tissue sections was mounted on electro positive glass slides. The streptavidinbiotin immunohistochemical method was used ${ }^{(18)}$, starting with overnight deparaffinized and cultivated with xylene then, rehydrated gradually with ethanol afterward washed by phosphate buffered saline (PBS). Masking the action of peroxidase was done by hydrogen peroxide $\left(\mathrm{H}_{2} \mathrm{O}_{2}\right) 3 \%$ for five minutes at room heat. For antigen retrieval, tissue sections were put in a cut-glass jar having sodium citrate buffer $(\mathrm{pH}$ 6.0) and heated two times in a microwave oven for five minutes each. The slides then permitted to cool and bathed with PBS. Staining for GRP78 antibody was performed consuming GRP78 mouse monoclonal antibody (Clone (A-10) sc-376768, Dako, Denmark). The dilution used was 1:50 in phosphate buffered saline.

Detection of antibody was performed using the universal kit (DAKO, Denmark) by PBS washing slides for 5 minutes and incubated with a secondary antibody which was biotinylated goat serum conjugated with sera of rabbit and mouse for thirty minutes. Sections were then clear up to five minutes in PBS then antigen-antibody monitoring through diaminobenzidine in PBS having forty percent $\mathrm{H}_{2} \mathrm{O}_{2}$. Sections were eroded for ten minutes under running tap water, then counterstained using Mayer's hematoxylin and finally mounted.

\section{Histomorphometric evaluation}

Immunopositivity for GRP78 was assessed by calculate approximately the ratio of stained cells in relative to the zone inspected in every field, by means of a Leica system for image analysis. The system composed of a color videotape, screen, the disc of computer attached to light microscope and Leica software. The analyzer was rectified mechanically to change the measurement parts (pixels) into micrometer units. The zone besides space fraction of GRP78 reactive areas sedated with reference to a fixed calculating border of area 11434.9 micrometer $^{2}$ using magnification (x200). Consuming the color detection, positive parts were covered in a blue binary color. Ten fields for each slide measured to be histomorphometrically estimated. Then mean values obtained from all samples.

\section{Statistical analysis}

Information was obtainable as mean and standard deviation (SD) measures. To compare more than two groups mean area percent we used the analysis of variance test. Tukey post hoc test multiple comparisons was used in the procedure of pairwise comparisons among the collections when Analysis of variance test is of importance. $\mathrm{P}$ value is important if not as much of or identical to 0.05 (P $\leq 0.05$ ). Arithmetical investigation was done by instate graph pad version 3.10 and Microsoft ${ }^{\circledR}$ excel 2007. 


\section{RESULTS}

\section{Immunohistochemical findings:}

GRP78 immunostaining was detected in cytoplasm of ductal cells and some serous acini of normal salivary gland. (fig., 1A). Regarding benign neoplasm, cytoplasmic GRP78 expression was detected in some ductal epithelial as well as myoepithelial cells of pleomorphic adenoma (fig., 1B). In Warthin's tumor, cytoplasmic GRP78 was detected in ductal epithelial cells lined the cystic spaces as well as in lymphocyte and lymphoblast of germinal center (fig., 1C). Regarding malignant neoplasm, in Ca ex PA, detection of GRP78 was in cytoplasm and nuclei of malignant epithelial cells as well as nuclear immunostaining of myoepithelial cell in the chondroid and myxoid tissues (fig., 2D). In MEC, for low grade, cytoplasmic and nuclear GRP78 staining was seen in epidermoid cells plus cytoplasmic expression of some mucous secreting cells as well as C.T stromal cells of low grade. In high grade MEC, GRP78 was found in cytoplasm and as perinuclear staining (fig., 2 E, F). In ACC, GRP78 was seen in cytoplasm and nuclei of neoplastic cells of cribriform pattern and in cytoplasm and perinuclear of neoplastic cells of tubular as well as solid patterns (fig.,2 G, H, I, respectively).

\section{Statistical results:}

The highest mean area percent of GRP78 immunoexpression was noted in highgrade mucoepidermoid carcinoma, followed by low grade one. The lowermost mean value logged in normal salivary tissue. Analysis of variance examination stayed extremely statistically significant difference $(\mathrm{p}<0.0001)$ among all groups. Tukey's post hoc experiment showed there is was no statistically significant difference between normal salivary gland tissue, PA and Warthin's tumor where the lowest area percent value recorded for normal followed by PA then Warthin's tumor. There was no statistically significant different between low and high grade MEC, both show the statistically significant highest mean area percent values. Followed by solid ACC then Ca ex PA. There was no statistically significant difference between cribriform and tubular patterns of ACC, both show the statistically significant higher mean area percent (Table 1, fig., 3).

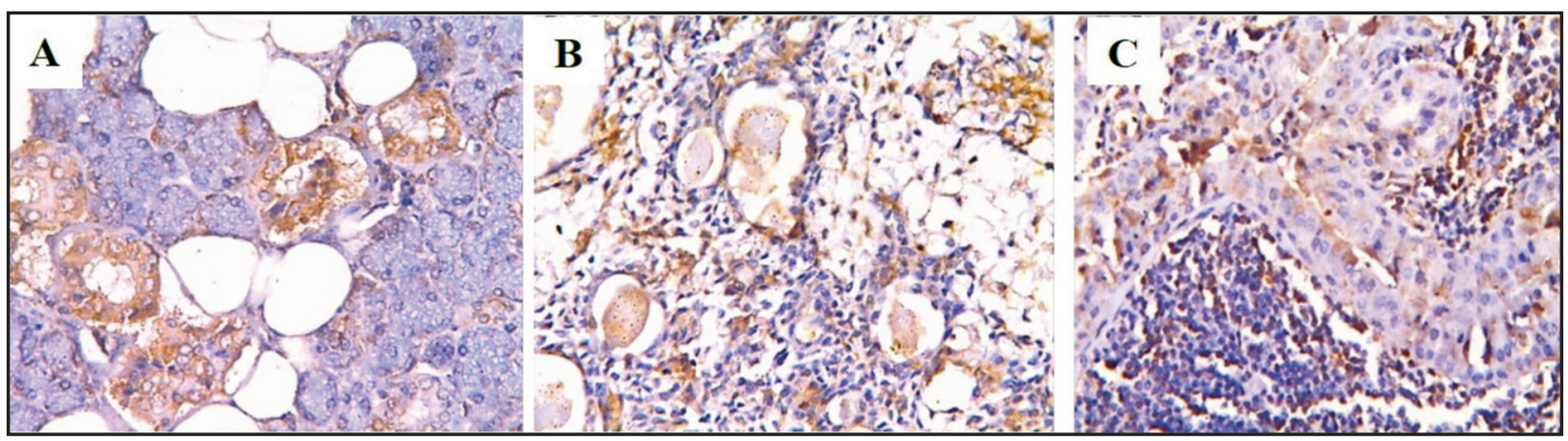

Figure (1) GRP78 immunostaining detected in the cytoplasm of ductal cells of normal salivary gland, A, GRP78 immunostaning of cytoplasm of some epithelial and myoepithelial cells, B, GRP 78 immunostaining of cytoplasm of double row of ductal epithelial cells, C, (GRP 78, X200). 


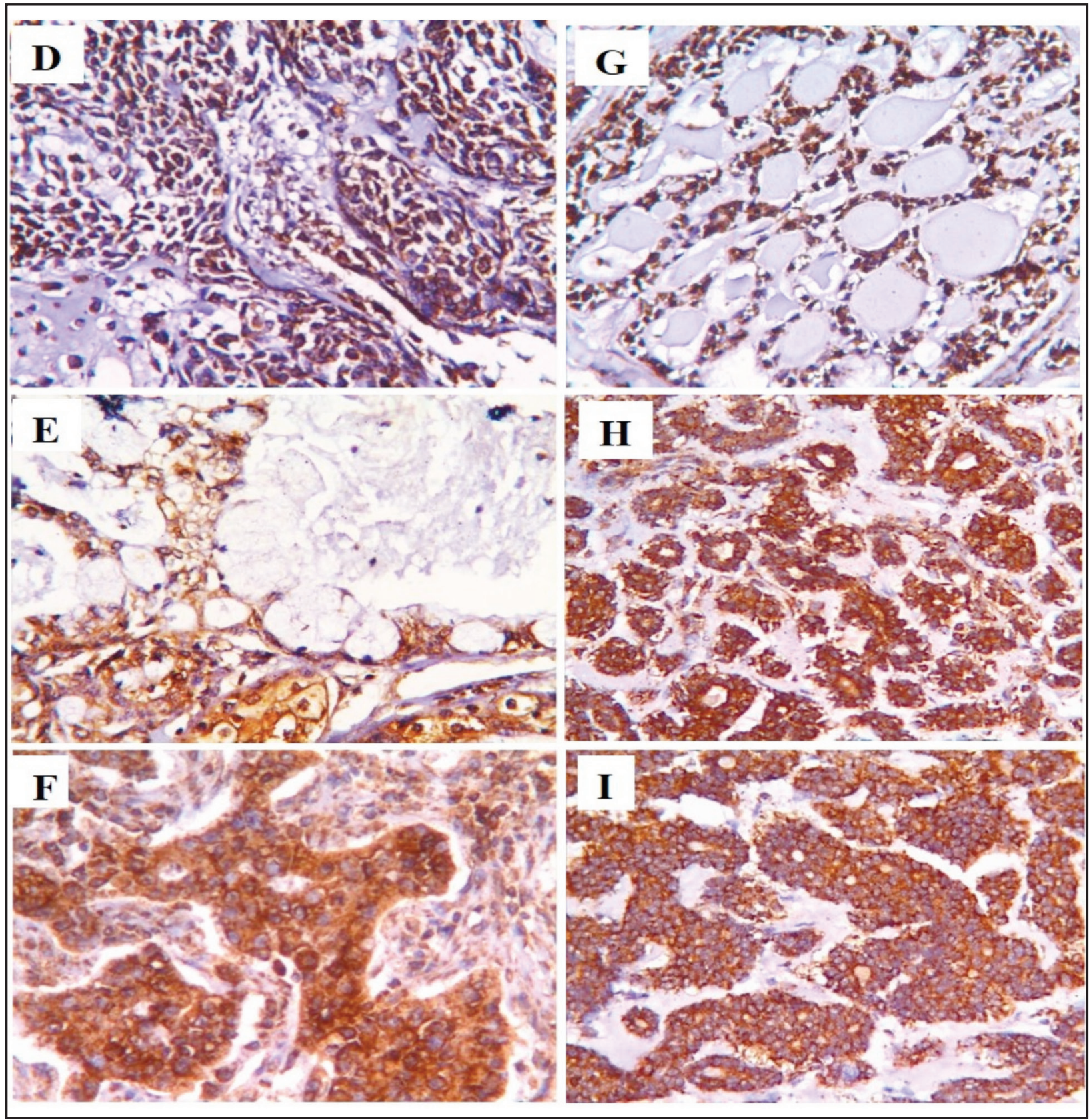

Figure (2) Cytoplasmic and nuclear GRP78 immunostaining in malignant epithelial as well as myoepithelial cells of Ca ex PA, D. GRP78 immunostaining of cytoplasm of epidermoid cells and mucous secreting cells in low grade MEC, E. Perinuclear and cytoplasmic immunostaining of epidermoid cells in high grade MEC, F, GRP78 immunostaining of cytoplasm and some nuclei of neoplastic cells of cribriform pattern, G. GRP78 immunostaining of perinuclear and cytoplasm of neoplastic cells of tubular structure, H, as well as solid patteru, I (GRP78, X200). 
Table (1): Area percent of immunoexpression in different groups (ANOVA test)

\begin{tabular}{|c|c|c|c|c|c|}
\hline Tumor type & Mean & S.D. & Min & Max & 14.42 \\
\hline Normal salivary gland & $10.13^{\mathrm{d}}$ & 3.69 & 6.25 & 16.21 \\
\hline PA & $14.80^{\mathrm{d}}$ & 1.21 & 12.91 & 19.03 \\
\hline Warthin's tumor & $13.05^{\mathrm{d}}$ & 3.71 & 9.96 & 60.20 \\
\hline Ca ex PA & $53.54^{\mathrm{b}, \mathrm{c}}$ & 7.45 & 44.94 & 72.75 \\
\hline MEC (low grade) & $63.44^{\mathrm{a}, \mathrm{b}}$ & 7.80 & 52.12 & 73.37 \\
\hline MEC (High grade) & $66.05^{\mathrm{a}}$ & 7.54 & 57.05 & 58.78 \\
\hline Cribriform ACC & $48.19^{\mathrm{c}}$ & 8.43 & 40.81 & 65.34 \\
\hline Tubular ACC & $51.04^{\mathrm{b}, \mathrm{c}}$ & 9.52 & 39.16 & 65.50 \\
\hline Solid ACC & $56.12^{\mathrm{a}, \mathrm{b}}$ & 9.56 & 42.80 & 6 \\
\hline
\end{tabular}

*Significance at $P<0.05$.

Tukey's post hoc assessment: means by different superscript letter are considerably statistically different.

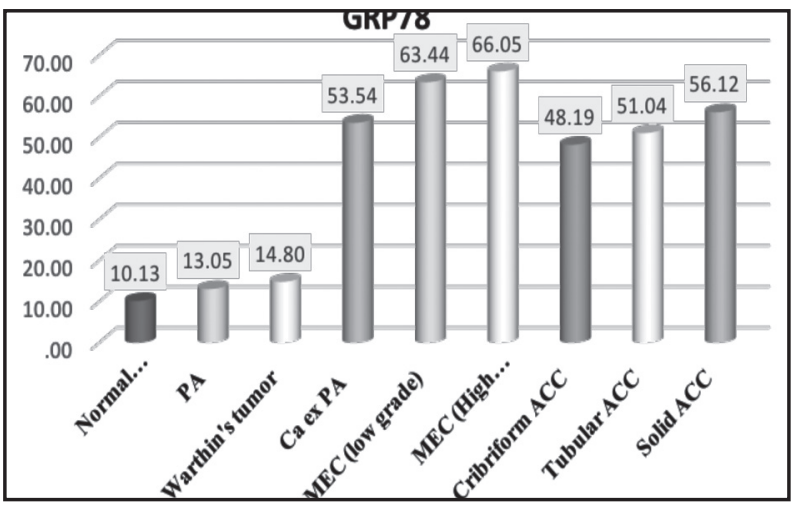

Figure (3) Column chart showing mean area percent of immunoexpression of different groups

\section{DISCUSSION}

Considering GRP78 immunoexpression results of our study, the statistically significant highest value of mean area percent recorded in malignant tumors then benign tumors. Meanwhile, the normal salivary gland tissues have the least value of mean area percent. This result is in accordance with previously demonstrated increase of GRP78 expression by 4 fold in malignant salivary gland tumors compared to benign ones ${ }^{(19)}$. Also, it was documented that the over-expression of GRP78 in oral sites was closely associated with increasing malignant possibility, with decreased GRP78 expression in leukoplakia than erythroplakia then verrucous lesion while oral cancer showed the highest mean GRP78 expression, speculating the essential role of GRP78 expression in the initial steps of oral carcinogenesis ${ }^{(20)}$.

Also, considering esophageal squamous cell carcinoma, it was observed that GRP78 expression was higher than in normal esophageal tissue. GRP78 overexpression in cancers in comparison with normal possibly demonstrating that the cancer cells were suffer of ER stress which triggered UPR to reestablish the homeostasis of ER and because of the point that cancerous cells form abundant distorted proteins which need GRP78 to form combination with ${ }^{(21,22)}$. The reduced Grp78 significantly decrease cell growth, migration, and invasion, proposing that this protein have oncogenic utilities ${ }^{(14,23,24)}$.

Nevertheless, opposite sound comes along, where GRP78 is inversely correlated with lung cancers and positive GRP78 expression patients have improved prognosis than individuals with negative expression. And also, in colorectal cancer, high GRP78 expression was related with increased survival ${ }^{(25,26)}$. 
This may be explained by the fact that GRP78 may show a suppressor role in controlling migration of tumor cell in hepatocellular cancer by inhibiting vimentin (an EMT broadly used maker, a common characteristic of highly invasive and metastatic cancerous cells) expression. Therefore, the character of GRP78 in cancer cell invasion and migration might differ through diverse types of cancer ${ }^{(27)}$.

GRP78 may work as a contrary mechanism according to a different type of cancer, this may be explained by that there are 3 chief sensors of ER stress, PERK, IRE1 $\alpha$ and ATF6. It has been thought that signals by IRE1 $\alpha$ and ATF6 have either a toxic or a protective role according to the form of stress, and PERK mediates lethal ER stress signs. The increasing expression of GRP78 acts to decrease activation of these ER sensors, contributing to being protective. Thus, the suppression of GRP78 will enhance the activation of ER stress signaling which lead to death of tumor cells ${ }^{(16,28)}$.

Regarding cellular expression of GRP78 in this study, it gave cytoplasmic expression of both normal salivary gland as well as benign tumors while it became nuclear, cytoplasmic and sometimes membranous expression in malignant tumors.

While GRP78 is mainly present in the perinuclear ER with the assistance of its C-terminal retention part, previous study have showen that in particular cell types or when cells exposed to stress, GRP78 can be relocated outside the ER, like the cytosol, the cell membrane, the mitochondria and nucleus, and even it can be secreted, where it utilizes new function on growth of cell and signaling ${ }^{(7)}$.

This may be explained that ER stress improves retention of Grp78 transcript through its intron 1, leading to formation of a new isoform of GRP78 (Grp78va) which miss the ER signal peptide and is present mainly in the cytosol. It shows cytoprotective function and also has the ability for UPR signaling regulation from the cytosol ${ }^{(7)}$.
The nuclear form of GRP78 has been associated with cellular homeostasis and therapeutic failure. It is attractive to guess that the nuclear form of GRP78 might prevent DNA damage through a specific monitoring mechanism in the nucleus ${ }^{(19,29,30)}$.

A correlation between high expression of membranous GRP78 and aggressive tumors was suggested. The low cell surface GRP78 in benign tumors compared to the malignant cells follows this concept. Also it was found that higher level of cell membrane GRP78 present in endometrial cancer patients than in the normal group ${ }^{(31,32)}$.

Increased cell surface GRP78 was found in many types of tumors including breast carcinoma, lung adenocarcinoma and colon adenocarcinoma. Also, the expression of membranous GRP78 has been reported in another tumor types like hepatocellular, gastric, prostatic carcinoma, and renal cell carcinoma, representing that cell surface GRP78 expression is accompanying with bad prognosis and/or poor outcome of patient ${ }^{(30,31,33-35)}$.

Cytoplasmic and/or nuclear presence of GRP78 expression in tumor cells is explained by that in normal circumstances, binding of GRP78 with the three various ER stress sensors ATF-6, PERK and IRE1 result in inactivation of them. The accumulation of unfolded proteins which stimulate ER stress results in GRP78 separation from the stress sensors and its plasma membrane translocation. High plasma membrane GRP78 expression on various types of cancer and decreased expression on normal cells belong to their characteristically raised ER stress levels within the cancerous cells ${ }^{(7,36)}$.

Furthermore, GRP78 translocation at the cell surface of cancer not normal cells have been shown, as it is thought to act as a regulating receptor of tumorigenic signaling, increase blood supply and viability of tumor cells ${ }^{(37,38)}$.

In the current study, GRP78 was detected in cytoplasm of normal acini, ducts as well as myoepithelial cells. This is in accordance to previous 
results where cytoplasmic GRP78 expression was identified in the acinar and ductal epithelial cells of normal salivary gland ${ }^{(15,39)}$. Moreover, it showed cytoplasmic expression in myoepithelial cells of the normal breast tissues. This was explained by that the cytoplasm of myoepithelial cells was packed with abundant endoplasmic reticulum where GRP78 was localized ${ }^{(40)}$.

Between the benign tumors examined in the present study, WT show higher mean area percent of GRP78 immunoexpression than PA with no statistically significant difference. This may be explained by presence of myoepithelial cells in PA where the myoepithelial cells known as natural tumor suppressors owing to their negative effect on several needs of tumor cells ${ }^{(41-43)}$.

Through the malignant tumors examined in this study, the highest GRP78 expression level was noted in MEC then ACC whereas the lowest mean value was recorded in Ca ex PA, although the difference between these tumors was not statistically significant. As mentioned before, salivary gland cancers with predominant myoepithelial elements (like ACC and Ca ex PA) are of low grade behavior, as compared with those devoid of myoepithelium (like MEC), which are considered high grade due to the tumor suppressor role of myoepithelial cells ${ }^{(1,43-46)}$.

Regarding MEC results in the present study, high grade MEC showed higher GRP78 area percent than low grade MEC, with no statistically significant difference between them. This is in accordance with previous study showed that GRP78 overexpression in the human lung carcinoma connected to the grade of differentiation. Poorly differentiated tumors show higher GRP78 expression than wellmoderately differentiated ones ${ }^{(47)}$. Also, it was found that GRP78 overexpression in head and neck squamous cell carcinoma tissues were related to the more aggressive status and poor prognosis ${ }^{(14,24)}$.

Regarding ACC results of the present study, the highest GRP78 expression was recorded in solid pattern of ACC then tubular whereas the lowest mean value was recorded in cribriform pattern with no statistically significant difference. This result is in agreement with previous one where expression of GRP78 was meaningfully associated with the histological growth pattern and grade of ACC. These results determined the role of ER stress in advancement of tumor, and GRP78 might be a prognostic marker in salivary ACC ${ }^{(15)}$. The solid pattern of ACC showed poor survival rate than the tubular and cribriform histopathological patterns ${ }^{(48,49)}$.

GRP78 was clarified as a bad prognostic marker for ACC patients, having a significant correlation with proliferation and angiogenesis. The GRP78 overexpression seemed to be related to a solid pattern, demonstrating no significant difference ${ }^{(16)}$.

\section{CONCLUSION}

The present study confirmed that GRP78 is considered as useful marker in diagnosis of malignancy of salivary gland and give strong indication for tumor aggressiveness.

\section{REFERENCES}

1. Goyal G, Mehdi S, Ganti A. Salivary gland cancers: biology and systemic therapy. Oncology. 2015; 29:773-80.

2. Badam RK, Kanth S, Raju S, Kotha SK, Rao M, Chandra KL. Current concepts of salivary gland tumors. J Orofac Sci. 2015; 7:76-9.

3. Sun L, Zhao Y, Zhou K, Freeze HH, Zhang YW, Xu H. Insufficient ER-stress response causes selective mouse cerebellar granule cell degeneration resembling that seen in congenital disorders of glycosylation. Mol Brain. 2013; 6:52-9.

4. Senft D, Ronai ZA. UPR, autophagy, and mitochondria crosstalk underlies the ER stress response. Trends Biochem Sci. 2015; 40:141-8.

5. Cook KL, Shajahan AN, Warri A, Jin L, Hilakivi-Clarke LA, Clarke R. Glucose-regulated protein 78 controls crosstalk between apoptosis and autophagy to determine anti estrogen responsiveness. Cancer Res. 2012; 72:3337-49.

6. Grkovic S, O'Reilly VC, Han S, Hong M, Baxter RC, Firth SM. Igfbp-3 binds grp78, stimulates autophagy and promotes the survival of breast cancer cells exposed to adverse microenvironments. Oncogene. 2013; 32:2412-20. 
7. Ni M, Zhang Y, Lee AS. Beyond the endoplasmic reticulum: atypical GRP78 in cell viability, signaling and therapeutic targeting. Biochem J. 2011; 434: 181-8.

8. Casas C. GRP78 at the centre of the stage in cancer and neuroprotection. Front Neurosci. 2017;11:177-91.

9. Dong D, Stapleton C, Luo B, Xiong S, Ye W, Zhang $\mathrm{Y}$, et al. A critical role for GRP78/BiP in the tumor microenvironment for neovascularization during tumor growth and metastasis. Cancer Res. 2011; 71: 2848-57.

10. Steelman LS, Chappell WH, Abrams SL, Kempf RC, Long J, Laidler P, et al. Roles of the RAF/MEK/ERK and $\mathrm{PI} 3 \mathrm{~K} / \mathrm{PTEN} / \mathrm{AKT} / \mathrm{mTOR}$ pathways in controlling growth and sensitivity to therapy-implications for cancer and aging. Aging. 2011; 3: 192-222.

11. Li Z and Li Z. Glucose regulated protein 78: A critical link between tumor microenvironment and cancer hallmarks. Biochim Biophys Acta. 2012; 1826: 13-22.

12. So AYL, de la Fuente E, Walter P, Shuman M, Bernales $\mathrm{S}$. The unfolded protein response during prostate cancer development. Cancer Metastasis Rev. 2009; 28: 219-23.

13. Huang TT, Chen YF, Tseng CE, Su YC, Ho HC, Lee MS, et al. Decreased GRP79 protein expression is a potential prognostic marker of oral squamous cell carcinoma in Tawan. J Formos Med Assoc. 2010; 109:326-37.

14. Xia F, Xu JC1, Zhang P, Zhang YY, Zhang QW, Chao $\mathrm{ZH}$, et al. Glusose-related protein 78 and heparanase expression in oral squamous cell carcinoma: correlation and prognostic significance. World J Surg Oncol. 2014; 12:121-8.

15. Jiang L, Huang S, Li W, Zhang D, Zhang S, Zhang W, et al. Expression of autophagy and ER stress-related proteins in primary salivary adenoid cystic carcinoma. Pathol Res Pract. 2012; 208:635-41.

16. Kaira K, Toyoda M, Shimizu A, Shino M, Sakakura K, Takayasu Y, et al. Expression of ER stress markers (GRP78/BiP and PERK) in adenoid cystic carcinoma. Acta Oto-Laryngologica. 2016; 136:1-7.

17. EL Naggar AK, Chan JKC, Grandis JR, Takata T, Slootweg PJ. WHO classification of tumors of the head and neck. 4th ed. Lyon: IARC Press; 2017.

18. Ramos-Vara JA, Miller MA. Technical aspects of immunohistochemistry. Vet Pathol. 2014; 51:42-87.

19. Bachar G, Raiter A, Gilat H, Feinmesser R, Hardy B. Apoptosis and cell surface GRP78 expression in benign and malignant parotid gland tumors. Head Neck Oncol. $2014 ; 6: 15-20$.
20. Lin CY, Chen WH, Liao CT, Chen IH, Chiu CC, Wang HM, et al. Positive association of glucose-regulated protein 78 during oral cancer progression and the prognostic value in oral precancerous lesions. Head Neck. 2010; 32:1028-39.

21. Zhang LH, Zhang X. Roles of GRP78 in physiology and cancer. J.Cell Biochem. 2010; 110:1299-305.

22. Niu Z, Wang M, Zhou L, Yao L, Liao Q, Zhao Y. Elevated GRP78 expression is associated with poor prognosis in patients with pancreatic cancer. Sci Rep. 2015; 5:16067-78.

23. Ren P, Chen C, Yue J, Zhang J, Yu Z. High expression of glucose-regulated protein 78 (GRP78) is associated with metastasis and poor prognosis in patients with esophageal squamous cell carcinoma. Onco Targets Ther. 2017; $10: 617-25$

24. Chiu CC, Lin CY, Lee LY, Chen YJ, Lu YC, Wang HM, et al. Molecular chaperones as a common set of proteins that regulate the invasion phenotype of headand neck cancer. Clin Cancer Res. 2011; 17:4629-41.

25. Wang Q, He Z, Zhang J, Wang Y, Wang T, Tong S, et al. Overexpression of endoplasmic reticulum molecular chaperone GRP94 and GRP78 in human lung cancer tissues and its significance. Cancer Detect Prev. 2005; 29:544-51

26. Thornton M, Aslam MA, Tweedle EM, Ang C, Campbell $\mathrm{F}$, Jackson R, et al. The unfolded protein response regulator GRP78 is a novel predictive biomarker in colorectal cancer. Int J Cancer. 2013; 133:1408-18.

27. Virrey JJ, Dong D, Stiles C, Patterson JB, Pen L, Ni M, et al. Stress chaperone GRP78/BiP confers chemoresistance to tumor-associated endothelial cells. $2008 ; 6: 1268-75$.

28. Wei PC, Hsieh YH, Su MI, Jiang X, Hsu PH, Lo WT et al. Loss of the oxidative stress sensor NPGPx compromises GRP78 chaperone activity and induces systemic disease. Mol Cell. 2012; 48:747-59.

29. Wang J, Gao X, Qin P, He H, Cai1 Z, Mu G, et al. Expression of glucose regulated protein 78 in human triple negative breast cancer and its clinical implications. Int $\mathrm{J}$ Clin Exp Pathol. 2016; 9:3134-42.

30. Misra UK, Pizzo SV. Ligation of cell surface GRP78 with antibody directed against the $\mathrm{COOH}$-terminal domain of GRP78 suppresses Ras/MAPK and PI 3-kinase/AKT signaling while promoting caspase activation in human prostate cancer cells. Cancer Biol Ther. 2010; 9: 142-52.

31. Ni M, Zhang YAS. Beyond the endoplasmic reticulum: atypical GRP78 in cell viability, signaling and therapeutic targeting. Biochem J. 2011; 434: 181-8. 
32. Zheng H, Takahashi H, Li X, Hara T, Masuda S, Guan Y, et al. Over-expression of GRP78 and GRP94 are markers for aggressive behavior and poor prognosis in gastric carcinomas. Hum Pathol. 2008; 39:1042-9.

33. Ciortea R, Malutan AM, Angheluta LM, Bucuri CE, Rada MP, Mihu D. GRP78 levels, regional fat distribution and endometrial cáncer. Rev Med Chil. 2016; 144:1577-83.

34. Rauschert N, Brandlein S, Holzinger E, Hensel F, MullerHermelink HK, Vollmers HP. A new tumor-specific variant of GRP78 as target for antibody-based therapy. Lab Invest. 2008; 88:375-86.

35. Fu W, Wu X, Li J, Mo Z, Yang Z, Huang W, Ding Q. Upregulation of GRP78 in renal cell carcinoma and its significance. Urology. 2010; 75:603-7.

36. Pfaffenbach KT, Lee AS. The critical role of GRP78 in physiologic and pathologic stress. Curr. Opin. Cell Biol. 2011; 23:150-6.

37. Su R, Li Z, Li H, Song H, Bao C, Wei J, Cheng L. Grp78 promotes the invasion of hepatocellular carcinoma. BMC Cancer. 2010; 10: 20-31.

38. Shenolikar S. Dangerous liaisons: flirtations between oncogenic BRAF and GRP78 in drug-resistant melanomas. J Clin Invest. 2014; 124:973-6.

39. Kim I, Xu W, Reed JC. Cell death and endoplasmic reticulum stress: disease relevance and therapeutic opportunities. Nat Rev Drug Discov. 2008; 7:1013-30.

40. Katsiougiannis S, Tenta R, Skopouli FN. Endoplasmic reticulum stress causes autophagy and apoptosis leading to cellular redistribution of the autoantigens Ro/Sjögren's syndrome-related antigen $\mathrm{A}$ (SSA) and La/SSB in salivary gland epithelial cells. Clin Exp Immunol. 2015; 181:244-52.

41. Nazeer J, Prakash V, Mandal S, Prakash A. Myoepithelial cells: Structure, function and role in tumor formation. Int J Dent Health Sci. 2014; 1: 155-60.

42. Chitturi RT, Veeravarmal V, Nirmal RM, Reddy BV. Myoepithelial cells (MEC) of the salivary glands in health and tumours. J Clin Diagn Res. 2015; 9: 14-8.

43. Shah AA, Mulla AF, Mayank M. Pathophysiology of myoepithelial cells in salivary glands. J Oral Maxillofac Pathol. 2016; 20: 480-90.

44. Yu M, Gou WF, Zhao S, Xiao LJ, Mao XY, Xing YN, et al. Beclin 1 expression is an independent prognostic factor for gastric carcinomas. Tumor Biol. 2013; 34:1071-83.

45. Arsov I, Adebayo A, Kucerova-Levisohn M, Haye J, MacNeil M, Papavasiliou FN, et al. A role for autophagic protein beclin 1 early in lymphocyte development. J Immunol. 2011; 186:2201-9.

46. Laurie SA, Licitra L. Systemic therapy in the palliative management of advanced salivary gland cancers. J Clin Oncol. 2006; 24:2673-8

47. Bell D, Roberts D, Kies M, Rao P, Weber RS, El-Naggar AK. Cell type-dependent biomarker expression in adenoid cystic carcinoma: biologic and therapeutic implications. Cancer. 2010; 116: 5749-56.

48. Wang M, Kaufman RJ. The impact of the endoplasmic reticulum protein-folding environment on cancer development. Nat Rev Cancer. 2014; 14:581-97.

49. Hu YW, Han W, Zhu R, Cao F, Ding HZ. Expression of GRP78 and KIAA1234 in gastric cancer and their prognostic value. Chin J Clin Oncol. 2016; 21:609-12. 